\title{
DERECHO, IDEOLOGÍA Y DISCURSO ${ }^{1}$
}

\author{
Law, ideology and discourse
}

Juan Pablo Zambrano Tiznado*

Resumen

Este trabajo pretende examinar las relaciones entre derecho, ideología y discurso. Para ello se asume la teoría sociocognitiva de la ideología de Teun van Dijk y el enfoque institucional acerca de la naturaleza del derecho de Joseph Raz explorando la posibilidad de la existencia de ideologías legales. A partir de un ejemplo, se muestra la imbricación del campo político con el campo de la justicia y se concluye que los jueces adhieren al menos a dos grupos ideológicos, uno de carácter político y otro de carácter profesional.

Palabras clave: Ideología, Grupos ideológicos, Ideología de los jueces, Texto sentencia.

Abstract

This paper aims to examine the relationship between law, ideology and discourse. To do this, the sociocognitive theory of Teun van Dijk's ideology is ascribed together with Joseph Raz's institutional approach to the nature of law by exploring the possibility of existence of legal ideologies. Starting from an example, we show the overlap between the political field with the field of justice and conclude that judges adhere to at least two ideological groups, one of a political nature and the other of a professional nature.

Key words: Ideology, Ideological groups, Ideology of judges, Sentence text.

\section{INTRODUCCIÓN}

El objetivo de este trabajo es examinar las relaciones entre derecho, ideología y discurso. Para ello se articula la teoría del sistema jurídico de Joseph Raz con las nociones de discurso e ideología de Teun van Dijk. Se trata entonces de hacer patente las relaciones entre estos conceptos y establecer un marco conceptual que permita estudiar al derecho como discurso. Así, el objetivo de este trabajo es relacionar la ideología con el derecho, entendiendo al derecho como una práctica discursiva.

El derecho en tanto discurso es una práctica social compleja porque se ve configurado por ciertas instituciones y determinadas estructuras sociales que establecen una relación dialéctica entre el evento discursivo y los demás elementos que lo configuran, entonces: el discurso moldea lo social y lo social moldea el discurso (Fairclough y Wodak, 367). Por ejemplo, la dictación de una norma jurídica implica un discurso particular que para ser comprendido requiere analizar la relación dialéctica existente entre la dictación de la nueva norma (en tanto práctica discursiva

\footnotetext{
${ }^{1}$ Este artículo forma parte del proyecto de investigación Fondecyt-Chile № 1110332: "Análisis del texto sentencia penal como signo de la cultura jurídico-judicial".
} 


\section{Juan Pablo Zambrano Tiznado}

particular) que ingresa al cuerpo de la legislación (sistema jurídico), y los aspectos institucionales y sociales que permitieron su dictación. Por cierto, realizar este análisis implica levantar categorías y utilizar una metodología que se centre en el estudio del texto: v.gr. el art. 102 del Código Civil o la sentencia rit 101-2005 permitiendo de este modo, visualizar el papel que juegan las ideologías en el derecho y el papel que tienen determinados operadores políticos y jurídicos en la forma en que comprendemos "nuestro derecho" (Raz, La ética, 256) 2 .

\section{IDEOLOGÍA Y DISCURSO}

Las teorías clásicas de la ideología se caracterizan por destacar su aspecto social. En Van Dijk (Ideología; Ideología y análisis del discurso, 9-36), sin embargo, la ideología es entendida, además, en su aspecto cognitivo. En su aspecto social, para Van Dijk una ideología es "el fundamento de las representaciones sociales compartidas por un grupo social" (Política, ideología y discurso, 17) mientras que, en su aspecto cognitivo, la ideología es "una representación mental almacenada en la memoria, que puede ser usada para actividades como la interpretación de acontecimientos y acciones, la comprensión de un discurso, o la producción de (inter)acciones" (Algunas notas, 37). Entonces, las ideologías son las creencias axiomáticas (Política, ideología y discurso, 21) que tiene un grupo social y que generan identidad y sentido de pertenencia al mismo tiempo que, en tanto representaciones mentales, permiten entender, interpretar y comprender los discursos de la comunidad ideológica a la que se pertenece y las ideologías de los demás grupos ideológicos.

Ahora bien, cualquiera que conozca la obra de Van Dijk se dará cuenta del pastichedel título de este trabajo con un artículo suyo titulado Política, ideología y discurso (2005). En él, su autor pretende especificar su teoría de la ideología a la política. En mi caso, pretendo realizar tal especificación al derecho. Sin embargo, con el título de este texto quiero significar algo más: una concepción acerca del derecho en donde el fenómeno jurídico constituye un subsistema del sistema político (Raz, $L a$ autoridad, 131-2; La ética, 221). En efecto, siguiendo a Raz (La ética, 220), el sistema político es uno más de los subsistemas que forman el sistema social, y todos ellos —el sistema jurídico, el sistema político y el sistema social— son normativos, aunque no se compongan únicamente de normas.

Es importante destacar que el enfoque institucional respecto de la cuestión de la naturaleza del derecho es consciente de que los sistemas político y jurídico se relacionan entre sí y precisamente esta sería su ventaja frente a enfoques rivales como el lingüístico y el centrado en la perspectiva del abogado (Raz, La ética, 220-221). Como afirma Raz (220), la adopción de este enfoque permite "examinar a los

\footnotetext{
${ }^{2}$ En una publicación anterior he sostenido, a propósito de la idea de "nuestro derecho", que el desafío de "la Teoría Analítica del Derecho posthartiana de alcanzar una conceptualización unívoca, abstracta y general de El Derecho, aparenta verse fracturada por la inclusión de una cuota de localidad idiosincrásica en su formulación" (Zambrano y Agüero, El 'cultural point of view', 390).
} 
abogados y a los tribunales respecto de su ubicación en la perspectiva general de la organización social y de las instituciones políticas".

\section{LAS IDEOLOGÍAS DEL DERECHO}

Van Dijk (Política, ideología y discurso, 24) clasifica las ideologías según el campo social en que funcionan. Así, en lo que él llama "el campo de la justicia" existirían "ideologías legales" (24). Aunque Van Dijk no desarrolla el punto, su teoría supone que el campo de la justicia es lo suficientemente autónomo como para diferenciarlo del campo político y de sus respectivas ideologías. Sin embargo, esta afirmación es parcialmente correcta como hemos mostrado a partir del enfoque institucional. En efecto, comprender al derecho como un fenómeno social (el de la normatividad), implica reconocer que en nuestras sociedades es la política la que mediante diversas prácticas le da sustrato a las creencias axiomáticas que tienen los operadores del sistema jurídico. Además, los discursos políticos sustentan determinadas creencias axiomáticas relativas al contenido de las normas, fijan procedimientos y al fin de cuentas permiten llamar a un sistema jurídico como democrático o autoritario. Entendidas así las cosas, rotular de democrático o autoritario a un sistema jurídico es solo la extensión de la calificación del sistema político en que un determinado sistema jurídico reside.

Podría objetarse que es posible entender la afirmación de Van Dijk como si afirmara que el sistema jurídico anglosajón (norteamericano e inglés) es ideológicamente distinto del sistema jurídico continental (chileno, español, colombiano, entre otros). Sin embargo, permanece en pie la suposición de que esas diferencias son producto de diversas ideologías legales (sea lo que sea que ello signifique) y no el producto de diferentes prácticas y discursos políticos.

\section{IDEOLOGÍA POLÍTICA Y DERECHO}

La vinculación entre la política, los políticos, sus prácticas y discursos por una parte y el derecho, los jueces y abogados, sus prácticas y discursos por otro, se ilustra mejor con un ejemplo.

En Chile, como en muchos países occidentales, los jueces para llegar a formar parte de los tribunales superiores requieren necesariamente del pronunciamiento positivo del Congreso y, evidentemente, es posible encontrar en los debates parlamentarios que se suscitan acerca de estas votaciones, la estructura polarizada del "cuadrado ideológico" (Van Dijk, Política, ideología y discurso, 30).

He elegido fragmentos de las opiniones de algunos senadores respecto del rechazo en el ascenso a la Corte Suprema del ministro Carlos Cerda y de la ministra Raquel Campusano y del debate pertinente a la supuesta política de acuerdos que debía ejercer el Ejecutivo para lograr la aprobación de los nombres que proponía. Para 
analizar los textos ${ }^{3}$ he utilizado algunas de las categorías analíticas y los dominios del discurso que utiliza Van Dijk (Política, ideología y discurso, 32- 44) en el análisis del discurso político.

\section{Ejemplificación/ilustración (argumentación)}

Se trata de ilustrar un punto de vista mediante un ejemplo o historieta. En este caso se discute la afirmación del vicepresidente de la Cámara alta senador Jaime Naranjo, quien ha acusado a la oposición de politizar el nombramiento de los jueces. El senador Pablo Longueira para negar la acusación utiliza como ejemplo el caso de la ministra Raquel Campusano.

El verdadero veto a los nombres que postulan al máximo tribunal lo ejerce silenciosamente el propio oficialismo, al realizar la presentación. La mejor jueza que ha habido en la historia del poder judicial fue la ministra Raquel Campusano y, lamentablemente, nunca llegó a la Corte Suprema porque investigó el caso Guzmán y procesó al socialista Marcelo Schilling.

En este caso además, el ejemplo se expresa de manera hiperbólica al afirmar que es "la mejor jueza que ha habido en la historia del Poder Judicial" la que ha sido objeto de un veto político.

\section{Polarización, categorización Nosotros-Ellos (significado)}

Por medio de esta estrategia semántica el senador socialista Jaime Naranjo acusa a la oposición (ellos) de votar de acuerdo con su propia ideología política:

Me sorprende que la Alianza no admita que el Ministro de Justicia debe conversar con ellos para consensuar los nombres. El problema es que este sistema le está haciendo mal al país porque la oposición lo ha politizado.

La cita permite además mostrar cómo la polarización nosotros-ellos es el resultado del uso cognitivo de la ideología y muestra cómo ella sirve para interpretar los discursos y actos de los otros grupos ideológicos.

Presuposición (significado)

Se trata, como expresa Van Dijk (Política, ideología y discurso, 43), "que las presuposiciones a menudo se usan para dar por establecida la verdad de tal proposición cuando en realidad no se establece en absoluto tal verdad". La cita corresponde al senador Alberto Espina quien afirma:

\footnotetext{
${ }^{3}$ Todas las citas textuales a senadores de la República se obtuvieron del artículo de prensa titulado Categórico respaldo del Senado a Pedro Pierry y Héctor Caamaño como nuevos integrantes de la Corte Suprema del 6 de agosto de 2006. Recuperado el 1 de mayo de 2011, desde http:/www.senado.cl/prontus_galeria_noticias/site/artic/20080129/pags/20080129120329.html 
Me gustaría que dijera cuál de los ministros propuestos es de la Concertación y cuál de la Alianza porque cuando se lanza acusación en el Senado y se dice que hay una especie de ping pong, en los nombramientos quisiera que fuera claro, porque estas personas no tienen forma de defenderse y se les insulta gratuitamente.

En este caso, el senador realiza una interesante movida argumental (argumentative moves), pues evita responder la acusación y prefiere presuponer que los jueces se sentirán insultados por ella.

Evidencia (significado, argumentación)

Se trata de sustentar un punto de vista mediante una evidencia que explique lo que se afirma. Esta evidencia puede provenir de la autoridad o de la propia constatación. En este ejemplo el senador Espina utiliza la evidencia "condena" para argumentar a favor del ascenso del juez Cerda: "Creo que en un momento extraordinariamente complejo en materia de DD.HH. él actuó correctamente. Las personas que fueron procesadas terminaron siendo condenadas".

Implicación (significado)

Se refiere a aquella información que los políticos no mencionan pero que está implícita. Los destinatarios que tienen los conocimientos, los valores y las actitudes comprenden en el discurso estos significados porque ellos forman parte del modelo mental que el destinatario tiene y que le permite comprender el discurso a cabalidad.

Lamento el resultado porque creo que el ministro Cerda reunía todas las cualidades profesionales: una gran probidad, una trayectoria impecable, un doctorado de excelencia y, en definitiva, como ha quedado claro en el debate, su valentía y su independencia en momentos muy difíciles en nuestro país en los años 80, marcar esa independencia y el respeto a los Derechos Humanos fueron, en definitiva, el detonador de que no hubiera contado con los votos necesarios.

En el ejemplo, el senador Frei se lamenta del rechazo de la postulación del juez Cerda sin indicar responsabilidades por ese resultado. Según su opinión, el rechazo es consecuencia tanto de su independencia como de la defensa de los derechos humanos que llevó a cabo en los años 80 . De este modo se deja implícito que quienes votaron por el rechazo no valoran la defensa de los derechos humanos que realizó el ministro Cerda en los tiempos del gobierno militar. Del mismo modo, en el caso de la jueza Campusano, la senadora Matthei también se lamenta del rechazo pese a los merecimientos. En el ejemplo - al igual que el senador Frei- no indica responsabilidades: "no puedo dejar de lamentar que la señora Raquel Campusano no haya llegado a la Suprema porque también lo merecía". 
Los ejemplos no son generalizables y solo muestran que en algunos casos se discutió el carácter ideológico de las razones de los rechazos. Sin embargo, ello no significa que cuando hubo consensos, o cuando no se puso en cuestión las argumentaciones de los votos, aquellas prácticas y discursos no hayan tenido el carácter de ideológicos. Me parece que debido al contexto de los eventos en que se producen las discusiones (sesiones del pleno del Senado, en que los tiempos, la forma de votar y en general todos los procedimientos vinculados, están regulados por un reglamento) es posible reconocer en las intervenciones de los senadores un discurso ideológico. Por lo demás, esto no es novedoso en la medida que se entienda al discurso político como completamente ideológico (Van Dijk, Política, ideología y discurso, 225). Con todo, lo que he querido destacar, es la marcada yuxtaposición expresada en el discurso de los senadores, entre lo político y lo jurídico. Es pues, esta considerable relación la que permite matizar la existencia de ideologías legales autónomas.

\section{LA IDEOLOGÍA DE LOS JUECES}

Me he centrado en los jueces porque constituyen el punto de partida del enfoque institucional (Raz, La ética, 221). Son los tribunales quienes en nuestras sociedades "administran justicia" y su existencia es muestra del conocimiento sociocultural (Van Dijk, Discurso y poder, 271) de la comunidad occidental de que los conflictos intersubjetivos de interés deben ser resueltos principalmente de forma pacífica por un tercero.

Los jueces en tanto grupo de profesionales comparten una determinada ideología, del mismo modo que lo hacen los periodistas, intelectuales o profesores (Van Dijk, Ideología y análisis del discurso, 4; Política, ideología y discurso, 24). Una de esas creencias axiomáticas es de naturaleza profesional y puede ser enunciada así: "es posible y deseable administrar justicia imparcialmente". Otra creencia axiomática (más velada) es su compromiso con el ideario de alguna tendencia política. Esta creencia podría enunciarse así: "las sentencias judiciales deben comunicar con claridad (aunque no de modo expreso) cuál es mi compromiso político". La primera creencia es afirmada por el sistema político en la medida en que hay leyes que regulan mecanismos de implicancia y recusación que permiten, por un lado, al juez sustraerse de un conflicto por estar implicado en él y; por otro, a los abogados solicitar su alejamiento del caso por las mismas razones. En cambio, la segunda creencia parece cuestionada por el sistema político. En efecto, los propios senadores, como se mostró en el ejemplo, parecen recriminarse por el uso de razones políticas para justificar los ascensos a la Corte Suprema. Entonces, la existencia de un Poder Judicial (en tanto poder de juzgar) "invisible y nulo" como diría Atria citando a Montesquieu (134) no asegura que los jueces sean inmunes a la política en la medida en que del cumplimiento de la segunda creencia axiomática depende su ascenso al Poder Judicial. En otras palabras, en Chile se llega a ser ministro de la Corte Suprema 
por compartir (o no) unas creencias axiomáticas con un determinado grupo en un cierto momento y por tener una biografía de prácticas coherentes.

Un aspecto interesante de la teoría de la ideología de Van Dijk (Política, ideología y discurso, 20) es que permite que una persona, un político por ejemplo, pueda pertenecer a varios grupos ideológicos y por tanto adherir simultáneamente a varias ideologías. La teoría también permite que un miembro del grupo concretice la creencia común de un modo distinto al que lo hace la mayoría de su grupo ideológico. Ese es, al parecer, el caso del senador Espina que, perteneciendo al grupo ideológico de la oposición, fue el único representante de su grupo que no voto en contra del ascenso del juez Cerda; de hecho, su argumento coincide con el del grupo ideológico que votó a favor del nombramiento: "Creo que en un momento extraordinariamente complejo en materia de DD.HH. él actuó correctamente". La diferencia respecto de su grupo puede significar que el senador Espina tenga, además de la ideología que comparte, otra creencia axiomática que comparte con los miembros de la concertación (por ejemplo, valorar las acciones judiciales en defensa de los derechos humanos) o simplemente que la forma en que él entiende la creencia compartida no implica contradicción con votar a favor del juez Cerda. Ahora bien, del mismo modo que un político, un juez puede pertenecer a varios grupos ideológicos. En el caso de los jueces, ellos comparten la membrecía al menos de dos grupos, el del poder judicial al que pertenecen y al de un determinado grupo político: los radicales, los liberales, los conservadores o los igualitaristas ${ }^{4}$.

Antes de continuar, una prevención. Para Raz, el inicio del enfoque institucional lo constituyen los jueces (órganos primarios) en su conjunto y no individualmente considerados. Del mismo modo, el interés que puede tener un analista del discurso en textos judiciales también es general, aunque estudie textos determinados ${ }^{5}$. Entonces, no se trata de que el analista a partir de una sentencia pueda concluir la ideología política de su autor, porque para efectos sistémicos esa investigación carece de valor, se trata más bien de que, a partir del estudio de un corpus, se pueda establecer la forma concreta en que se relaciona un determinado sistema jurídico con un determinado sistema político, para de este modo conocer mejor los rasgos que caracterizan "nuestro derecho". Así, aunque el ejemplo se refiere a votaciones particulares tiene un alcance sistémico al mostrar la plausibilidad de la segunda creencia axiomática. De este modo se matiza la existencia de ideologías legales autónomas y se muestra la posibilidad de que un lector perteneciente a un determinado grupo ideológico "lea" rasgos ideológicos en el texto sentencia.

\footnotetext{
${ }^{4}$ Para rotular a los diversos modelos político-constitucionales, entre las muchas opciones disponibles, utilizo la propuesta de Gargarella (2005).

${ }^{5}$ En este sentido, el problema es metodológico. Se trata que al establecer un corpus, el analista utilice un criterio que permita cierta representatividad respecto del conjunto.
} 


\section{SENTENCIA Y ANÁLISIS DEL DISCURSO}

Se puede esperar que las prácticas ideológicas de los jueces se textualicen de algún modo en la sentencia (Van Dijk, Algunas notas, 44) y ella debiera dar cuenta, al menos, de las dos ideologías a las que cada juez adhiere. Sin embargo, la creencia axiomática de la imparcialidad obliga a que la ideología política se oculte y solo se visibilice la ideología profesional. Esto significa que la sentencia, en tanto discurso, "expresa, reproduce y formula" (Van Dijk Ideología y análisis del discurso, 3; Política, ideología y discurso, 26) ideologías contradictorias. Es posible encontrar sentencias imparciales y radicales al mismo tiempo que sentencias imparciales y liberales. Entonces, cualquier estudio acerca de las sentencias en tanto discurso obliga a prestar atención a los aspectos relevantes de la situación social (contexto) que la controlan (Van Dijk, Discourse and context, 128).

Ahora bien, al realizar el análisis de una sentencia conviene tener claridad respecto de algunas distinciones. En palabras de Correas (112), hay que distinguir el "discurso del derecho" del "discurso jurídico". El primero se refiere a las normas jurídicas, mientras el segundo, "[hace] referencia [ ] a los discursos, prescriptivos o descriptivos, que, o bien acompañan el derecho en los mismos textos, o bien constituyen metadiscursos respecto de él" (Correas, 112). Un ejemplo de discurso jurídico entonces es, precisamente este trabajo ${ }^{6}$. En el caso de la sentencia penal, la descripción de los hechos constituye un discurso jurídico mientras que la resolución constituye un discurso del derecho. Para Correas además se debe distinguir el "sentido deontológico" del "sentido ideológico" del derecho. Así, en la parte resolutiva de una sentencia (discurso del derecho) existe un sentido deontológico, en la medida que ese "texto" utiliza operadores deónticos o puede reducirse a alguno de ellos; del mismo modo, en la medida en que la norma jurídica textualiza alguna ideología es posible estudiar el sentido ideológico del derecho (Correas, 115-117). En cambio, en la narración de los hechos no es posible estudiar el sentido deontológico del derecho porque no hay tal, sin embargo se pueden estudiar las ideologías jurídicas (Correas, 119), o más bien, las ideologías políticas o morales que se textualizan en dichos discursos.

\footnotetext{
${ }^{6}$ Para Correas, las definiciones legales, como el art. 102 del Código Civil que define el matrimonio corresponden a discursos jurídicos porque carecen de sanción. En mi caso, prefiero usar la regla de reconocimiento como criterio para distinguir las normas que son discurso del derecho de aquellas que son discurso jurídico. En este sentido, las normas morales o políticas cuyo uso está autorizado por normas jurídicas constituyen, por este reenvío, discurso del derecho. Sin embargo, los jueces pueden utilizar discrecionalmente normas que no pertenecen al sistema jurídico. Relativo a este punto, Raz afirma "el panorama resultante consiste en que los tribunales aplican tanto consideraciones jurídicas (por ejemplo, positivistas, autoritativas) como no jurídicas. Se basan tanto en razones ejecutivas como en razones deliberativas, aunque el derecho pertenezca solamente al primer tipo" (La ética, 224).
} 


\section{CONCLUSIONES}

He mostrado cómo es posible darle contenido a la noción de "nuestro derecho" utilizando herramientas de análisis del discurso. Se trata de hacer emerger las formas concretas en que un determinado sistema jurídico se vincula con un sistema político.

Estas características pueden resultar interesantes porque permitirían evidenciar continuidades y discontinuidades en los rasgos característicos de "nuestro derecho", al mismo tiempo que puede mostrar la evolución de una determinada ideología o incluso el modo en que una determinada creencia axiomática pasa a constituirse con el tiempo en un conocimiento sociocultural.

Una de las principales dificultades para realizar un análisis del discurso jurídico lo constituye la determinación de un corpus de sentencias. Luego, determinado el corpus, la ideología de la imparcialidad es el principal reto que debe afrontar el analista. En efecto, su alto grado de institucionalización obliga a ser cuidadosos en la selección de los textos, de modo que permitan efectivamente visibilizar la ideología expresada de manera ritual. Sin embargo, pese a las dificultades, creo que las posibilidades que brinda la utilización de herramientas de análisis del discurso son variadas en la medida que la selección adecuada de un corpus permita, parafraseando a Mackie (Agüero y Zambrano, La narración, 30; Integración metodológica), reconstruir el modo en que hemos construido lo bueno y lo malo en nuestra sociedad.

Universidad de La Frontera*
Departamento de Ciencias Jurídicas
Av. Francisco Salazar No1145, casilla54 D, Temuco (Chile)
juanpablo.zambrano@ufrontera.cl

\section{OBRAS CITADAS}

Agüero, Claudio y Zambrano, Juan Pablo. "La narración en las sentencias penales", Revista Universum 24 No 2, 2009: 28-41.

"Integración metodológica para el estudio del texto de las sentencias penales chilenas", Revista Convergencia 17 № 54, 2010: 69-91.

Atria, Fernando. "Jurisdicción e independencia judicial: el poder judicial como poder nulo", Revista de Estudios de la Justicia 5, 2004: 119-141.

Correas, Oscar. Crítica de la ideología jurídica. Ensayo sociosemiológico. Ciudad de México: Universidad Nacional Autónoma de México, 1993.

Fairclough, N. y Wodak R. "Análisis crítico del discurso", en El discurso como interacción social. Teun van Dijk (comp). Barcelona: Gedisa, 2000.

Gargarella, Roberto. Los fundamentos legales de la desigualdad: el constitucionalismo en América (1776-1860). Madrid: Siglo XXI, 2005. 
Raz, Joseph. La ética en el espacio público. Barcelona: Gedisa, 2001.

— La autoridad del derecho. Ensayos sobre derecho y moral. Ciudad de México: UNAM, 1985.

Van Dijk, Teun. Discurso y poder. Barcelona: Gedisa, 2009.

Discourse and context. A sociocognitive. Approuch. New York: Cambridge University Press, 2008.

"Ideología y análisis del discurso", en Utopía y Praxis Latinoamérica $10 \mathrm{~N}^{\circ} 29$, 2005: 9-36.

"Política, ideología y discurso", Quórum académico N², 2005: 15-47.

- Ideología. Una aproximación multidisciplinaria. Madrid: Gedisa, 1998.

"Algunas notas sobre la ideología y la teoría del discurso", Semiosis 5, 1980: 37-53.

Zambrano y Agüero. "El cultural point of view en una sentencia penal". Frónesis 16 $\mathrm{N}^{\mathrm{o}}$ 2, 2009: 385-392. Disponible en:

http://www.senado.cl/prontus_galeria_noticias/site/artic/20080129/pags/20080 129120329.html. Recuperada el 01 de mayo de 2011. 